Fifth International Conference on Sustainable Construction Materials and Technologies. http://www.claisse.info/Proceedings.htm

\title{
CHARACTERIZATION OF ENHANCED POZZOLANIC BIOMASS ASH
}

\author{
Eman H. Elbuaishi and P.S.Mangat \\ Materials and Engineering Research Institute, Sheffield Hallam University, Sheffield \\ S1 1WB, UK \\ e-mail: b4041209@my.shu.ac.uk, acespm1@my.shu.ac.uk
}

\begin{abstract}
ASTRACT
The environmental concerns of carbon emissions by the energy industry have led to a change in the way energy is generated. Biomass and co-firing coal and biomass are now considered as the most promising technology and renewable energy source.This paper is a part of ongoing research investigating the use of Enhanced Biomass Ash (EBA) generated from Drax power station (UK) in order to promote its usage as a supplementary cementitious material. The chemical and mineralogical compositions of ash were characterized by X-ray Fluorescence (XRF) and X-ray Diffraction (XRD) techniques. The strength activity index (SAI) of enhanced biomass ash mortar with Partial replacement of cement at $25 \%$ was also investigated and compared with commercial coal fly ash (CFA) mortar. The XRF results showed that the chemical composition of enhanced biomass ash is similar to class $\mathrm{F}$ fly ash according to American Standard Testing and Materials (ASTM) C618 and satisfies the main chemical composition requirements of European Standard (EN450-1). The results also showed that the enhanced biomass ash can be considered reactive as it contains $84 \%$ amorphous materials and its activity index at 28 and 90 days met the EN450-1 specifications. This indicates that the incorporation of biomass ash in concrete may give similar properties to concrete with coal fly ash.
\end{abstract}

Keywords: Biomass; compressive strength; fly ash; pozzolanc activity

\section{INTRODUCTION}

Fly ash released from coal combustion in electric power stations has been effectively used to replace a portion of cement in concrete production to reduce the environmental footprint of cement production and produce durable concrete. However, a quantity of $\mathrm{CO}_{2}$ is released to the atmosphere during the coal burning process(Tkaczewska \& Małolepszy 2009). Therefore, due to increasing concerns about greenhouse gas emission, there has been a move to change the way energy is generated by employing innovative techniques to generate renewable energy. Combustion of biomass and co- 
firing coal and biomass are considered the most promising technology for producing power using renewable energy sources(Shearer \& Kurtis 2015; Wang \& Baxter 2007; Barbosa et al. 2013). Consequently, the growing use of this technology releases a huge amount of new class fly ash that differs from those of coal combustion in their quality, chemistry and mineralogy. Coal fly ash almost has uniform composition as it results from coal burning. In contrast, the characteristics of biomass fly ash differ due to variety of its sources and depend on combustion conditions (fixed or fluidized beds), biomass sources (wood, herbaceous, rice husk, ets) and the location where the ash is collected (fly ash or bottom ash) (Rajamma et al. 2009; Chowdhury et al. 2015; Berra et al. 2015). The term "biomass" generally describes solid organic materials used to generate energy such as wood, grass and straw, therefore, similar characteristics should not be expected for fly ash generated from different sources or collected from different plants(Rajamma et al. 2009; Shearer et al. 2016). Generally, wood-based biomass burning is the main source of electricity in Europe which is considered the largest importer and consumer of wood in the world whereas the UK is by far the biggest wood consumer in Europe. It has been reported that about 15 million tonnes of wood were burnt in the UK and Drax power station burns the majority of biomass. In 2014/2015 it burned around 9 million tonnes of wood and in 2015, more than 20\% global wood pellets were burnt by the same company(Biofuelwatch 2016; Flach et al. 2016).Currently, most of the biomass ash is disposed of in landfills without any control and needs adequate management system as an industrial waste. Incorporation of biomass ash as a supplementary cementitious material could be one strategy as the practice of biomass combustion is increasing. However, most of the international standards such as ASTM C618 and EN450-1, that specify requirements for utilization of fly ash in concrete, only accept the use of ash that is released from coal combustion. Recently, EN 450-1 approved the use of fly ash obtained from co-combustion biomass up to $20 \%$ of the total fuel whereas pure biomass is still not included in this standard. It has been reported in the literature that utilization of coal fly ash as a partial replacement of cement not only reduces its disposal at landfill, but it improves the long term strength and durability properties of concrete. Thus, the question arises if incorporation of biomass fly ash in cement may give similar properties to concrete as with coal fly ash. Unlike coal fly ash, limited studies have been conducted to investigate the use of biomass ash in the concrete industry; however, most of the research has focused on the ash generated from co-combustion of biomass and coal rather than pure biomass ash. An extensive study to examine the effect of co-fired biomass fly ash on several concrete properties including strength and durability was conducted by Wang et al. They concluded that the performance of co-fired biomass fly ash is comparable to and in some cases better than coal fly ash. The results also showed that the pozzolanic reaction mechanism of biomass and coal fly ash is similar (Wang \& Baxter 2007). Such other studies have reported promising results indicating that the exclusion of biomass ashes from concrete industry might be inappropriate (Wang, Baxter, et al. 2008; Wang, Llamazos, et al. 2008; Rajamma et al. 2009; Tkaczewska \& Małolepszy 2009; Wang \& Baxter 2007).

This paper aims to characterize an Enhanced biomass pulverised ash obtained from Drax Power station in order to determine its potential as a supplementary cementitious material in concrete production. The objective of this study was to investigate the 
chemical, mineralogical composition and the pozzolanic activity index which indicate how the material will perform when added to cement.

\section{EXPERIMENTAL PROGRAMME}

\subsection{Materials}

An enhanced Pozzolanic biomass ash identified as (EBA) generated in Drax power station by burning 5 tonnes of coal fly ash with 30 tonnes of wood pellets by proportion. Combustion of wood pellets produces low ash content of around 1-2 \%. Thus, 30 tonnes of wood pellets produce 0.6 tonnes biomass fly ash which combines with 5 tonnes of coal fly ash used in the combustion process. Standard coal fly ash identified as (CFA) conforming to EN450, which is used in concrete production. Both materials were supplied in $25 \mathrm{Kg}$ drums by Power Minerals Ltd. Ordinary Portland cement (CEM I: 52.5 N) conforming to EN 197-1 supplied by Frank-key Group, Sheffield, UK was used as the primary binder in this investigation. Local sharp medium grade siliceous sand was supplied by Frank-key Group, Sheffield, UK. It was sieved through a $2.36 \mathrm{~mm}$ mesh before using in the mixtures.

\subsection{Experimental techniques}

\subsubsection{Chemical and Mineralogical Characterization}

$\mathrm{X}$-ray Fluorescence (XRF) technique was used to determine the chemical compositions of the two types of fly ash by using Philips PW2400 XRF spectrometer. The mineralogical compositions of the fly ash samples were determined by X-ray Diffraction (XRD) analysis. A Philips $\mathrm{X}$-Pert diffractometer with a $\mathrm{Cu} \mathrm{K} \alpha$ radiation source ( $40 \mathrm{KV}, 40 \mathrm{~mA}$ and wavelength $\lambda=0.1540 \mathrm{~nm}$ ) was used. Each sample was loaded into a separate XRD flat plate sample holder for a 30 minute scan between $\left(10^{\circ}\right.$ $80^{\circ}$ ) and the data were collected over an angle $2 \theta$. The percentage weights of amorphous content in both ashes were determined by Rivetveld refinement method. It was conducted by adding $10 \%$ standard silicon to obtain the proportion of silica in the amorphous phase.

\subsubsection{Physical Characterization}

The ash particle size distribution (PSDs) was measured using Malvern Mastersizer 3000 analyser with dry dispersion laser diffraction. Nitrogen adsorption by Micromeritics, ASAP $2020 \mathrm{M}$ volumetric Analyser using BET method was used to determine specific surface areas. The pozzolanic behaviour expressed as the strength Activity Index (SAI) was used to measure the reactivity of fly ash. It involves measuring the 28, 90 days compressive strength of fly ash cement mortar relative to control 100\% OPC mortar. The control OPC mortar was prepared according to BS EN $450-1$ by mixing $1350 \mathrm{~g}$ sand, $450 \mathrm{~g}$ Portland cement and $225 \mathrm{~g}$ water. The blended fly ash mortars were prepared in the same manner except that the Portland cement was replaced with $25 \%$ of fly ash by weight .The flow table tests on workability were conducted according to EN 1015-3 standard before casting the prism samples in 40x40x $160 \mathrm{~mm}$ prism moulds. The specimen were demoulded after $24 \mathrm{~h}$ and cured in 
tap water at $20^{\circ} \mathrm{C}, 60 \% \mathrm{RH}$ until the age of testing. The prisms were first tested in three point bending mode then each part was tested under compression (equivalent cube) according to BS EN 196.1. The average strength results of the three prisms were used to calculate the strength activity index (SAI) as follows:

$$
\mathrm{SAI}=\left(\frac{A}{B}\right) * 100 \%
$$

Where $\mathrm{A}$ is the average compressive strength of each blended fly ash-cement mortar $(\mathrm{MPa})$ and $\mathrm{B}$ is the average strength of the control OPC mortar (MPa) at the same age.

\section{RESULTS AND DISCUSSION}

\subsection{Chemical and Mineralogical Characterization}

The major chemical elements of the ashes obtained by XRF analysis are presented in Table1. Considering that no specific standard covers biomass fly ash, its properties were compared with the requirements for coal fly ash as specified in BS EN 450-1 (BS EN 450 2012) and ASTM C618-12 (ASTM C618 2010). Table 1 shows that both ashes are comprised of $\mathrm{SiO}_{2}$ and $\mathrm{Al}_{2} \mathrm{O}_{3}$ as the silica and alumina are the important components in the cementitious and pozzolanic reactions. The CFA relatively contains higher amounts of silicon dioxide $\left(\mathrm{SiO}_{2}\right)$, aluminium oxide $\left(\mathrm{Al}_{2} \mathrm{O}_{3}\right)$ and iron oxide $\left(\mathrm{Fe}_{2} \mathrm{O}_{3}\right)$ compared to EBA which might result in better pozzolanic and mechanical strength properties. The latter is much richer in calcium oxide $\mathrm{CaO}$, alkali sodium and potassium oxides $\left(\mathrm{Na}_{2} \mathrm{O}, \mathrm{K}_{2} \mathrm{O}\right)$. Both ashes have content of main oxides $\left(\mathrm{SiO}_{2}+\mathrm{Al}_{2} \mathrm{O}_{3}\right.$ $+\mathrm{Fe}_{2} \mathrm{O}_{3}$ ) greater than $70 \%$ and total calcium content, represented by calcium oxide $\mathrm{CaO}$, lower than $10 \%$. Thus, both ashes meet the requirement of main oxides with $73.04 \%$ and $81.35 \%$ for EBA and CFA respectively and the total calcium content requirement with $8.10 \%$ and $3.10 \%$ for EBA and CFA respectively. Therefore, both would be classified as Class F according to ASTM C618-12 based on their chemical composition. The alkali content (expressed as total alkali equivalent $=\mathrm{Na}_{2} \mathrm{O}+0.66$ $\mathrm{K}_{2} \mathrm{O}$ ) for both ashes were below the acceptable limit in BS EN $450-1(\leq 5 \%$ by mass) with $4.23 \%$ and $2.24 \%$ for EBA and CFA respectively. However, the high alkali content of EBA in general could inhibit their use for mitigation of alkali-silica reaction. The other chemical components of biomass fly ash met the BS EN 450-1 requirements of $\mathrm{SO}_{3}=0.17<3 \%, \mathrm{MgO}=0.46<4 \%, \mathrm{P}_{2} \mathrm{O}_{5}=0.75<5 \%$.

Qualitative XRD analyses determined the main crystalline phases. The XRD patterns of EBA given in Figure 1 show the presence of quartz, calcia and hematite as the major mineral components. The main phases identified for CFA were quartz and mullite as shown in Figure 2. The Rivetveld refinement results showed that EBA sample consisted of $84 \%$ amorphous material whereas the CFA ash sample consisted of $88 \%$ amorphous material. Since the reactive component of fly ash is related to the noncrystalline (amorphous) phase, therefore, both ashes can be considered reactive as they consisted of $84 \%, 88 \%$ amorphous phases respectively. 
Table 1.Chemical analyses of fly ashes

\begin{tabular}{ccc}
\hline Element & $\begin{array}{c}\text { Enhanced biomass } \\
\text { ash (EBA) }(\text { wt. \%) }\end{array}$ & $\begin{array}{c}\text { Coal fly ash (CFA) } \\
\text { (wt. \%) }\end{array}$ \\
\hline $\mathrm{SiO}_{2}$ & 41.46 & 47.64 \\
$\mathrm{Al}_{2} \mathrm{O}_{3}$ & 23.49 & 25.32 \\
$\mathrm{Fe}_{2} \mathrm{O}_{3}$ & 8.10 & 8.39 \\
$\Sigma\left(\mathrm{SiO}_{2}+\mathrm{Al}_{2} \mathrm{O}_{3}+\mathrm{Fe}_{2} \mathrm{O}_{3}\right)$ & 73.05 & 81.35 \\
$\mathrm{MgO}$ & 2.27 & 2.11 \\
$\mathrm{SO}_{3}$ & 0.17 & - \\
$\mathrm{TiO}_{2}$ & 1.48 & 0.57 \\
$\mathrm{CaO}_{\mathrm{K}} \mathrm{O}$ & 8.10 & 3.10 \\
$\mathrm{P}_{2} \mathrm{O}$ & 5.57 & 3.16 \\
$\mathrm{Na} O$ & 0.75 & 0.22 \\
$\mathrm{MnO}$ & 0.56 & 0.16 \\
$\mathrm{ZnO}$ & 0.46 & - \\
$\mathrm{SrO}$ & 0.12 & - \\
$\mathrm{BaO}$ & 0.25 & 0.11 \\
$\mathrm{LOI}$ & 0.21 & 0.36 \\
\hline
\end{tabular}

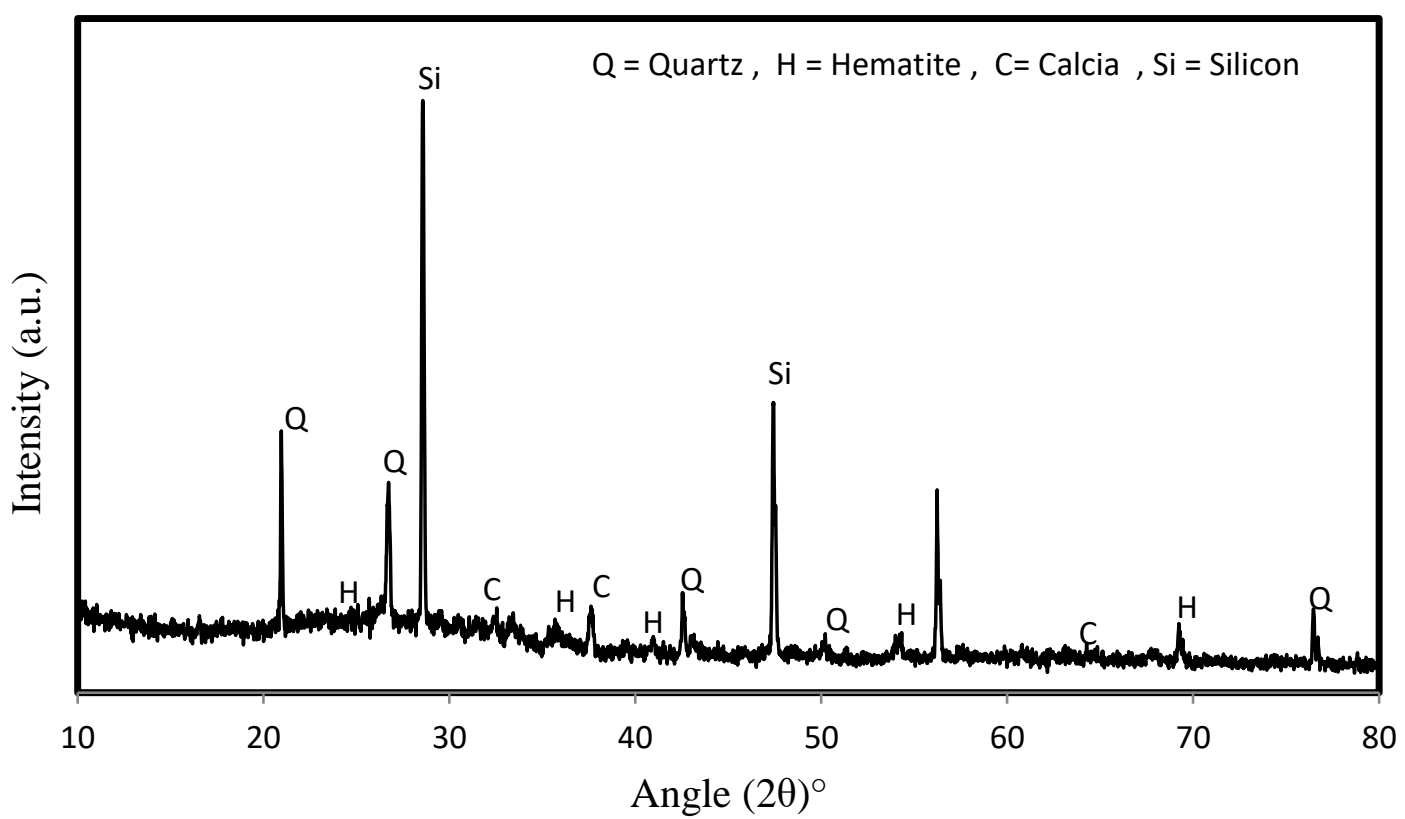

Figure 1. XRD Patterns of enhanced biomass fly ash 


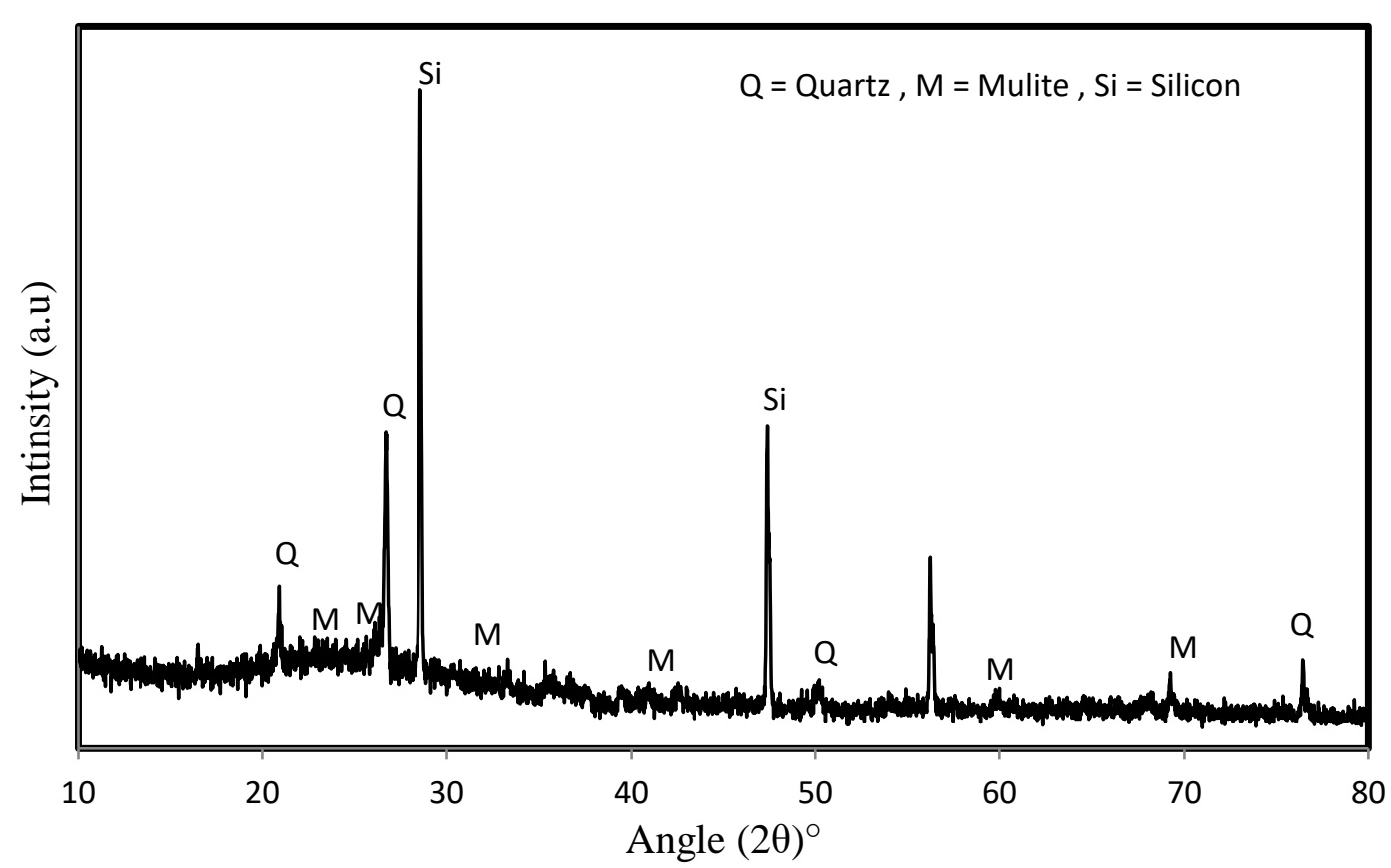

Figure 2. XRD Patterns of coal fly ash

\subsection{Physical Characterization}

\subsubsection{Particle Size Distribution}

The particle size distributions (PSDs) of both ashes determined by means of laser diffraction are shown in Figure 3. The analysis revealed that the biomass fly ash particles are coarser than coal fly ash particles. Coal fly ash had a lower median diameter $\left(\mathrm{d}_{50}=17.3 \mu \mathrm{m}\right)$ than biomass fly ash $\left(\mathrm{d}_{50}=49.7 \mu \mathrm{m}\right)$. The maximum particle size was $670 \mu \mathrm{m}$ for biomass fly ash and about $350 \mu \mathrm{m}$ for coal fly ash. The distribution of EBA is unimodal and the most numerous ranges were around $100 \mu \mathrm{m}$ whereas CFA distribution appeared to be triple modal.

\subsubsection{Specific Surface Area (SSA)}

Table 2 shows the specific surface areas of both ashes as determined by nitrogen adsorption using BET method. It is clear that the biomass fly ash has higher surface area compared to coal fly ash. This can be due to irregular and porous nature of the biomass fly ash particles especially if the quantity of unburned material was relatively high.

Table 2.Specific Surface Area of fly ashes

\begin{tabular}{|c|c|}
\hline Sample & Surface area $\left(\mathrm{m}^{2} / \mathrm{g}\right)$ \\
\hline EBA & $6.38 \pm 0.055$ \\
\hline CFA & $3.055 \pm 0.023$ \\
\hline
\end{tabular}



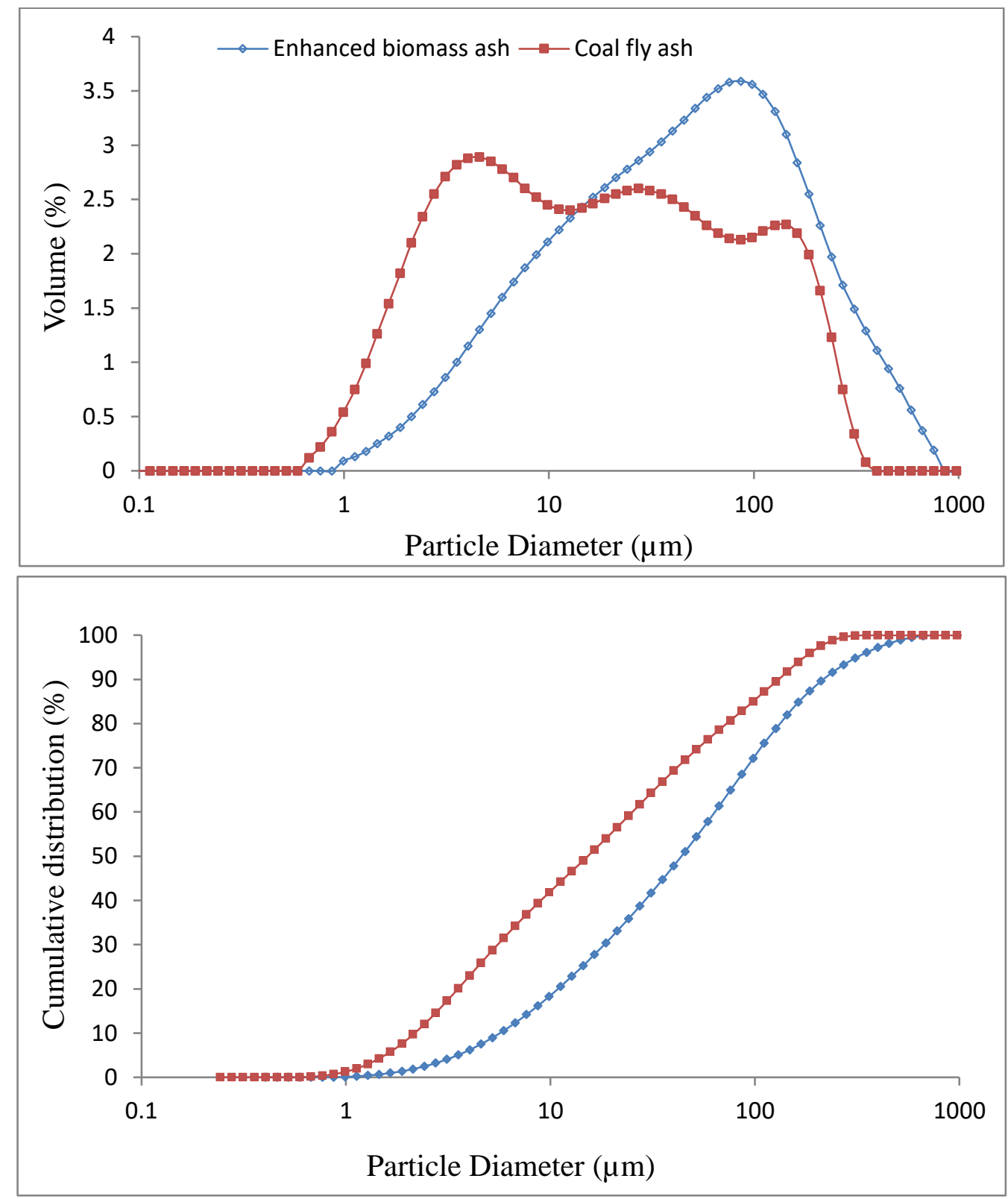

Figure 3.Particle size distributions of EBA and CFA

\subsubsection{Strength Activity Index}

The compressive strength and activity index (SAI) of both ashes are presented in Tables 3. CFA shows considerably higher SAI than EBA. At 28 days, the SAI for CFA and EBA is $99 \%$ and $85 \%$ respectively whereas it is $109 \%$ and $95.3 \%$ at 90 days. The superior strength performance of CFA compared to EBA could be attributed to its fineness as revealed by particle size distribution results. According to BS EN 450-1 standard, both ashes satisfy the strength activity requirements since their activity index at 28 and 90 days is greater than $75 \%$ and $85 \%$ respectively. Therefore, EBA can be 
suitable as a supplementary cementitious material as its activity index is within the required limits.

Table 3. Compressive strength and activity index

\begin{tabular}{|l|c|c|c|c|}
\hline \multicolumn{1}{|c|}{ Sample } & $\begin{array}{c}\text { 28-days } \\
\text { compressive } \\
\text { strength (MPa) }\end{array}$ & $\begin{array}{c}\text { Activity Index } \\
\text { at } \\
\text { 28-day } \%\end{array}$ & $\begin{array}{c}\text { 90-days } \\
\text { compressive } \\
\text { strength (MPa) }\end{array}$ & $\begin{array}{c}\text { Activity } \\
\text { Index at } \\
\text { 90-day \% }\end{array}$ \\
\hline OPC & 37.18 & 100 & 40.64 & 100 \\
\hline $25 \%$ EBA & 31.67 & 85 & 38.75 & 95.3 \\
\hline $25 \%$ CFA & 36.9 & 99 & 44.7 & 109 \\
\hline
\end{tabular}

\section{CONCLUSIONS}

An enhanced pozzolanic biomass ash and control samples of standard coal fly ash were investigated to determine the chemical and mineralogical compositions by $\mathrm{X}$-ray Fluorescence (XRF) and X-ray Diffraction (XRD) techniques. The physical properties of particle size distribution, specific surface areas and strength activity index were also investigated. The following conclusions were drawn based on these experimental results:

1. The enhanced biomass ash (EBA) is similar to class F coal fly ash on the basis of chemical composition according to ASTM C618.Its total oxides content of $\left(\mathrm{SiO}_{2}+\mathrm{Al}_{2} \mathrm{O}_{3}+\mathrm{Fe}_{2} \mathrm{O}_{3}\right)$ is $73.05 \%$ which is a typical value for pozzolanic materials used in cement production.

2. XRD results indicate that the mineralogical structure of both ashes is mainly amorphous with the presence of quartz, calcia and hematite as crystalline phases in EBA. The main phases identified in CFA are quartz and mullite.

3. The enhanced biomass fly ash can be considered reactive as it has $84 \%$ amorphous content.

4. Particle size distribution analyses show that the enhanced biomass ash has coarser particles than coal fly ash whereas its surface area is higher due to the porous nature of the particles.

5. The strength activity index of enhanced biomass ash at 28 and 90 days satisfies the EN450-1 specification. This indicates that the incorporation of biomass ash in cement may give similar properties to concrete with coal fly ash.

\section{REFERENCES}


ASTM C618, 2010. Standard Specification for Coal Fly Ash and Raw or Calcined Natural Pozzolan for Use. Annual Book of ASTM Standards, (C), pp.3-6.

Barbosa, R. et al., 2013. Concretes containing biomass ashes : Mechanical, chemical , and ecotoxic performances. Construction and Building Materials, 48, pp.457-463. Available at: http://dx.doi.org/10.1016/j.conbuildmat.2013.07.031.

Berra, M., Mangialardi, T. \& Paolini, A.E., 2015. Reuse of woody biomass fly ash in cement-based materials. Construction and Building Materials, 76, pp.286-296. Available at: http://dx.doi.org/10.1016/j.conbuildmat.2014.11.052.

Biofuelwatch, 2016. Biomass FAQ. , (August), pp.1-14. Available at: https://www.biofuelwatch.org.uk/2013/biomass-faq-2/.

BS EN 450, 2012. Fly ash for concrete Part 1 : Definition, specifications and conformity criteria. BS EN Standards.

Chowdhury, S., Mishra, M. \& Suganya, O., 2015. The incorporation of wood waste ash as a partial cement replacement material for making structural grade concrete: An overview. Ain Shams Engineering Journal, 6(2), pp.429-437. Available at: http://dx.doi.org/10.1016/j.resconrec.2011.02.002.

Flach, B. et al., 2016. EU-28 Biofuels Annual 2016. Global Agricultural Information Network, (June 2016), p.42.

Rajamma, R. et al., 2009. Characterisation and use of biomass fly ash in cementbased materials. Journal of Hazardous Materials, 172, pp.1049-1060.

Shearer, C.R. et al., 2016. Alkali-activation potential of biomass-coal co-fired fly ash. Cement and Concrete Composites, 73, pp.62-74. Available at: http://dx.doi.org/10.1016/j.cemconcomp.2016.06.014.

Shearer, C.R. \& Kurtis, K.E., 2015. Use of Biomass and Co-Fired Fly Ash in Concrete. ACI Materials Journal, V. 112, (112), pp.209-218.

Tkaczewska, E. \& Małolepszy, J., 2009. Hydration of coal - biomass fly ash cement. Construction and Building Materials, 23(7), pp.2694-2700. Available at: http://dx.doi.org/10.1016/j.conbuildmat.2008.12.018.

Wang, S., Llamazos, E., et al., 2008. Durability of biomass fly ash concrete : Freezing and thawing and rapid chloride permeability tests. Fuel, 87, pp.359364.

Wang, S. \& Baxter, L., 2007. Comprehensive study of biomass fly ash in concrete : Strength, microscopy, kinetics and durability. Fuel Processing Technology, 88, pp.1165-1170.

Wang, S., Baxter, L. \& Fonseca, F., 2008. Biomass fly ash in concrete : SEM , EDX and ESEM analysis. Fuel, 87, pp.372-379. 